\title{
Pain Management by Meditation: A Naturopathy Approach
}

\section{Viroj Wiwanitkit*}

Faculty of Medicine, Surin Rajabhat University, Thailand

Pain is an important unwanted sensation. For sure, everyone cannot avoid pain in lifespan. How to manage and decrease pain is the big topic in pain medicine. Several new drugs are fund by medical scientists and applied in pain control. Nevertheless, the classical ancient science concept to manage pain is still the hidden jewel [1,2]. The use of naturopathy concept in pain management should be mentioned. Using of meditation for relieving of pain is a classical practice in natural medicine. Based on the concept that pain occurs from brain, the use of medication that can affect brain function can be an interesting way for pain management. Zeidan et al. recently reported that "Mindfulness meditation, a practice premised on directing nonjudgmental attention to arising sensory events, reduces pain by engaging mechanisms supporting the cognitive control of pain" [3]. Decreased pain after a short meditation practice has just been reported by Tonelli and Wachholtz [4]. The usefulness of meditation for pain management can be expected. However, Grant noted that the actual "meditative analgesia" required further study on its exact physiological process [5].

\section{References}

1. Myers CD, White BA, Heft MW (2002) A review of complementary and alternative medicine use for treating chronic facial pain. J Am Dent Assoc 133: 1189-1196.

2. Chan PS, Wong MM (2004) Physicians and complementary-alternative medicine: training, attitudes, and practices in Hawaii. Hawaii Med J 63: 176181

3. Zeidan F, Adler-Neal AL, Wells RE, Stagnaro E, May LM, et al. (2016) Mindfulness-Meditation-Based Pain Relief Is Not Mediated by Endogenous Opioids. J Neurosci 36: 3391-3397.

4. Tonelli ME, Wachholtz AB (2014) Meditation-based treatment yielding immediate relief for meditation-naïve migraineurs. Pain Manag Nurs 15: 36-40.

5. Grant J (2014) Meditative analgesia: the current state of the field. Ann N Y Acad Sci 1307: 55-63.
*Corresponding author: Viroj Wiwanitkit, Faculty of Medicine, Surin Rajabhat University, Thailand, Tel: + 6624132436; E-mail: wviroj@yahoo.com

Received March 23, 2016; Accepted March 24, 2016; Published March 28, 2016

Citation: Wiwanitkit V (2016) Pain Management by Meditation: A Naturopathy Approach. J Pain Manage Med 2: e102.

Copyright: ( 2016 Wiwanitkit V. This is an open-access article distributed under the terms of the Creative Commons Attribution License, which permits unrestricted use, distribution, and reproduction in any medium, provided the original author and source are credited. 